\title{
28 Research Suare \\ Rural-Urban Disparities In Birth Interval Among Women of Reproductive Age In Nigeria
}

Anthony Ike Wegbom

Rivers State University

Adetomi Bademosi

Rivers State University

Clement Kevin Edet

Rivers State University

Green Kinakanwo

University of Port Harcourt Teaching Hospital

Leesi Sapira-Ordu

Rivers State University

Adeniyi Francis Fagbamigbe ( $\nabla$ franstel74@yahoo.com )

University of Ibadan

\section{Research Article}

Keywords: Short birth interval, Disparities, associated factors, rural and urban, Nigeria.

Posted Date: January 27th, 2022

DOI: https://doi.org/10.21203/rs.3.rs-1281387/v1

License: (c) (i) This work is licensed under a Creative Commons Attribution 4.0 International License.

Read Full License

Version of Record: A version of this preprint was published at Scientific Reports on October 19th, 2022. See the published version at https://doi.org/10.1038/s41598-022-22142-y. 


\section{Abstract}

Background: Nigeria like most developing nations still faced with a higher rate of short birth interval (SBI), and its associated consequences, such as adverse maternal and child health outcomes. This study aimed to determine the distribution and factors associated with SBI in rural and urban Nigeria.

Methods: The data for this study were extracted from the 2018 Nigeria Demographic and Health Survey. Statistical analyses were descriptive analysis and binary logistic model.

Results: The proportion of SBI in rural and urban Nigeria were $20.7 \%$ and $20.3 \%$ respectively. Women age, geopolitical region, education level, and the number of children ever born were significantly associated with SBI in rural and urban Nigeria. Maternal Wealth index and antenatal care visits were only significant in rural Nigeria after controlling for other factors. Higher odds of SBI for middle class women than poor women ( $A O R=1.19,95 \% \mathrm{Cl}=1.06-1.35)$, and increase in ANC visits reduces the odds of having SBI: 4-7 visits (AOR=0.87, 95\% $\mathrm{Cl}=0.77-0.98)$ and $>7$ visits (AOR=0.83, 95\% $\mathrm{Cl}=0.69-0.99$ ).

Conclusion: There were slight disparities in the prevalence of short birth intervals in rural and urban areas. Wealth index and ANC visits were only significant in rural Nigeria. Public health awareness campaigns should be strengthened to drive the importance of birth spacing techniques such as the utilization of modern contraceptives and breastfeeding in all the geo-political regions and across all the age strata. Women particularly those residing in the rural areas should be encouraged to advance their education to at least secondary level and enlightened on the importance of ANC.

\subsection{Introduction}

Birth spacing, also known as an inter-birth interval (IBI), or inter-pregnancy interval refers to how soon after a prior pregnancy a woman becomes pregnant or gives birth again. Optimal birth spacing (defined as inter-birth interval length of 24-59 months) is incontrovertibly linked to better health outcomes for both mothers and babies [1-3]. The World Health Organization (WHO) currently recommends an interval between the last live birth and the next pregnancy of at least 24 months [4], and any birth less than this is considered a short birth interval (SBI). Short or long birth intervals lead to adverse maternal, perinatal, neonatal, and child health outcomes $[5,6]$. Short birth interval is associated with under-five mortality and low birth weight (Wegbom et al., 2020; Wegbom et al., 2019). Globally, it is estimated that $25 \%$ of births still occur at intervals less than 24 months, and most of these births were observed in Central Asia (33\%) and Sub-Saharan Africa (20\%) [9].

The in Nigeria according to the 2018 Nigeria Demographic and Health Survey stood at $25 \%$ with a median birth interval of 30.9 months [10]. This suggests that Nigeria, like other developing nations, still is faced with a high rate of short birth intervals. Other African countries with similar rates include Rwanda: $20 \%$, Uganda: $25.3 \%$, Cameroon: $21.3 \%$ and Ethiopia: $24.9 \%$, and these high rates were attributed to lack of access to family planning options [11]. A study in Abuja, the capital city of Nigeria reported that $50 \%$ of women had birth to pregnancy intervals of fewer than 24 months, while 14 (3.5\%) had birth to pregnancy 
intervals of greater than 60 months [1]. A similar study in Enugu, Nigeria also reported that the median inter-birth interval was 21.5 months [2].

A few factors have been reported to be associated with birth intervals. Some of these may be direct factors such as frequency of sexual activity, use of contraceptives, postpartum in fecundability, abortion, and sterility while indirect factors may include socioeconomic and cultural factors [12, 13]. Interbirth interval is also influenced by sociodemographic, economic, and birth history [6]. Fayehun et al. reported that the type of contraceptives used, living in rural or urban settings, wealth index, husbands' occupation, and sex of preceding children determined birth intervals [14]. Having more female children and the birth of a female as the last child significantly reduced birth intervals in the quest for a male child [14]. Use of contraceptives for birth spacing was also seen to be affected by son preference where the last child born being a female, a woman would like to use a short-acting contraceptive in order not to wait too long to get a male child [6].

While adequate birth spacing is considered a very significant factor for the health of women and their children [11], inadequate birth spacing was rated as the highest risk African women faced during pregnancy compared to other pregnancy-related events [15]. Some studies in Nigeria and other nations have also shown a significant association between preceding birth interval and under-five mortality [1620]. But in Nigeria, studies sparse that have looked at the determinants of the short birth interval using nationally representative data such as NDHS. Existing studies were Hospital-based [2, 21-23], and each of them was only limited to the city or town in which the Hospital is located. This study bridged the gap by estimating the determinants of short birth interval at the national level using NDHS data.

Given the above, it is important to gain a deeper understanding of the disparities existing among women living in rural and urban Nigerians in terms of interbirth interval. This study, therefore, aimed to determine the distribution and factors associated with short birth intervals in rural and urban Nigeria.

\subsection{Methods}

\subsection{Data Source}

The data for this study were extracted from the 2018 Nigeria Demographic and Health Survey (2018 NDHS) conducted by the National Population Commission (NPC) and ICF international. Being a national survey, it elicits information from women and men of reproductive age across the 36 states and the Federal Capital Territory (FCT) Abuja, nominated through a stratified two-stage cluster sampling technique. The NDHS, like other Demographic and Health Surveys (DHS) is conducted every five years.

\subsection{Data}

The data involved 41821 women residing in rural and urban Nigeria, extracted from women data of 2018 NDHS.

\subsection{Study variables}


The outcome variable in this study was preceding birth interval recoded as $<24$ months and $\geq 24$ months. This is based on the definition of the World Health Organization [4]. The explanatory variables were sociodemographic and health care seeking characteristics.

The explanatory variables and their categories were:

Mother's age: $<20 / 20-29 / 30-39 / \geq 40$ years.

Mother's Religion: Christianity/ Islam/ Others.

Current Region of residence: North-central/ North-east/ North-west/ South-east/ South-south/ South-west.

Current place of residence: Urban/rural.

Mother's educational level: None/primary/secondary/higher.

Marital status: Never married/married.

Wealth index: Poor/middle/rich.

Number of children ever born: 0-2/ 3-4/ > 4 .

Antenatal care visits: None/1-3/4-7/>7 visits

\subsection{Data analysis and statistical technique}

We analyzed the data using univariate, bivariate and multivariate techniques. At the univariate level, the proportion was used to describe the characteristics of the respondents; at the bivariate technique level, chi-square was utilized to assess the association between the characteristics and the birth interval; while binary logistic regression was fitted at the multivariate level to determine the influence of this factors on birth interval to explain the disparities in the birth interval between rural and urban women.

The outcome variable, the birth interval was categorized and coded as ( $\geq 24$ months $=0$ and $<24$ months $=1$ ) to model logistic regression. Firstly, we described the characteristics. Secondly, we assessed the association between the explanatory variables and the birth interval; and lastly, only the significant variables were included in the binary logistic regression model. Three logistic regression models were fitted for the study: the entire country, rural Nigeria, and urban Nigeria. To account for the complex nature of the DHS data, we adjusted for sampling weight, clustering, and stratification. The measure of associations was odds ratio, and its statistical significance was assessed at $95 \%$ confidence interval, excluding unit and P-value $<0.05$. All analysis was done using Stata version 15.0 (StataCorp, College Station, TX).

The logistic regression model is expressed as: 
$\operatorname{In}\left[\frac{p}{1-p}\right]=\beta_{0}+\sum_{i=1}^{k} \beta_{i} X_{i}$

Where $p$ is the probability of an event to occur (having a short birth interval) and 1-p is the probability of the event not to occur (not having a short birth interval), $\frac{p}{1-p}$ is the "odds" of occurrence of the event against its non-occurrence. $\beta_{i}$ and $X_{i}$ are the regression coefficient of the explanatory variables and the explanatory variables (sociodemographic factors) respectively; and $\beta_{0}$ is the constant for the logistic regression model.

\subsection{Results}

The distributions of the characteristics and their association with birth interval are shown in Table 1. The results show that all factors are significantly associated with short birth intervals across Nigeria. $(P<0.05)$. The proportion of $<24$ months and $\geq 24$ months birth interval were respectively $20.6 \%$ vs $79.4 \%$ for Nigeria, $20.3 \%$ vs $79.7 \%$ for urban Nigeria and $20.7 \%$ vs $79.3 \%$ for rural Nigeria, as shown in figure 1 .

\section{Table 1: Characteristics and Association of respondents with Birth Interval in Nigeria}




\begin{tabular}{|c|c|c|c|c|}
\hline Characteristics & $\begin{array}{l}\geq 24 \text { months } \\
\text { Number (\%) }\end{array}$ & $\begin{array}{l}<24 \text { months } \\
\text { Number (\%) }\end{array}$ & Chi-square & P-value \\
\hline Overall & $20084(79.4)$ & $5196(20.6)$ & & \\
\hline Place of Residence & & & 0.703 & 0.402 \\
\hline Rural & $12625(79.3)$ & $3299(20.7)$ & & \\
\hline Urban & $7459(79.7 \%)$ & $1897(20.3)$ & & \\
\hline Maternal age (years) & & & 2155.2 & 0.000 \\
\hline$<20$ & $156(65.0)$ & $84(35.0)$ & & \\
\hline $20-29$ & $5862(75.7)$ & $1878(24.3)$ & & \\
\hline $30-39$ & $8008(80.9)$ & $1896(19.1)$ & & \\
\hline$\geq 40$ & 6058 (81.9) & $1338(18.1)$ & & \\
\hline Religion & & & 253.9 & 0.014 \\
\hline Christianity & 8919 (79.7) & $2269(20.3)$ & & \\
\hline Islam & $10990(79.3)$ & $2869(20.7)$ & & \\
\hline Others & $175(75.1)$ & $58(24.9)$ & & \\
\hline Region & & & 861.6 & 0.000 \\
\hline North Central & $3770(82.2)$ & $816(17.8)$ & & \\
\hline North East & $3810(78.0)$ & $1074(22.0)$ & & \\
\hline North West & $5340(78.5)$ & $1462(21.5)$ & & \\
\hline South East & $2242(75.0)$ & $747(25.0)$ & & \\
\hline South South & $2191(78.2)$ & $610(21.8)$ & & \\
\hline South West & $2731(84.9)$ & $487(15.1)$ & & \\
\hline Educational level & & & 209.1 & 0.004 \\
\hline No education & $8759(78.9)$ & $2345(21.1)$ & & \\
\hline Primary & $3915(81.3)$ & $900(18.7)$ & & \\
\hline Secondary & $5808(79.0)$ & $1542(21.0)$ & & \\
\hline Higher & $1602(79.7)$ & $409(20.3)$ & & \\
\hline Marital status & & & 29.5 & 0.018 \\
\hline Not married & $18392(79.3)$ & $4811(20.7)$ & & \\
\hline
\end{tabular}




\begin{tabular}{|lllll|}
\hline Wealth index & $1692(81.5)$ & $385(18.5)$ & & \\
\hline Poor & & & 83.9 & 0.002 \\
\hline Middle & $8684(79.1)$ & $2295(20.9)$ & & \\
\hline Rich & $4259(79.1)$ & $1123(20.9)$ & & \\
\hline Number of children ever born & & $1778(19.9)$ & & 0.001 \\
\hline $0-2$ & $3685(78.5)$ & $1011(21.5)$ & & \\
\hline $3-4$ & $6798(80.0)$ & $1695(20.0)$ & & \\
\hline$>4$ & $9601(79.4)$ & $2490(20.6)$ & & \\
\hline Antenatal care visits & & & 13.1 & \\
\hline None & & & \\
\hline $1-3$ & $3674(79.0)$ & $975(21.0)$ & & \\
\hline $4-7$ & $2490(77.9)$ & $705(22.1)$ & & \\
\hline$>7$ & $5414(80.5)$ & $1309(19.5)$ & & \\
\hline
\end{tabular}

Table 2: Factors associated with short birth interval in Nigeria, Rural and Urban Nigeria 


\begin{tabular}{|c|c|c|c|c|c|c|c|c|c|}
\hline \multirow[t]{2}{*}{ Factors } & \multicolumn{3}{|c|}{ Nigeria } & \multicolumn{3}{|c|}{ Rural Nigeria } & \multicolumn{3}{|c|}{ Urban Nigeria } \\
\hline & COR & AOR & $\begin{array}{l}95 \% \mathrm{Cl} \\
\text { for AOR }\end{array}$ & COR & AOR & $\begin{array}{l}95 \% \mathrm{Cl} \\
\text { for } \\
\text { AOR }\end{array}$ & COR & AOR & $\begin{array}{l}95 \% \\
\mathrm{Cl} \\
\text { for } \\
\mathrm{AOR}\end{array}$ \\
\hline
\end{tabular}

\section{Place of residence}

$\begin{array}{llll}\text { Urban } & 1.00 & 1.00 & \\ \text { Rural } & 1.03 & 1.12 & 0.96- \\ & & & 1.16\end{array}$

\section{Maternal age \\ (years)}

\begin{tabular}{|c|c|c|c|c|c|c|c|c|c|}
\hline$<20$ & 1.00 & 1.00 & & 1.00 & 1.00 & & 1.00 & 1.00 & \\
\hline $20-29$ & $0.52^{\star}$ & 0.40 * & $\begin{array}{l}0.34- \\
0.47\end{array}$ & $0.53^{*}$ & $0.39 *$ & $\begin{array}{l}0.33- \\
0.47\end{array}$ & $0.49 *$ & $0.37 *$ & $\begin{array}{l}0.27 \\
0.51\end{array}$ \\
\hline $30-39$ & $0.36^{*}$ & $0.22 *$ & $\begin{array}{l}0.19- \\
0.27\end{array}$ & $0.38 *$ & $0.24^{\star}$ & $\begin{array}{l}0.19- \\
0.30\end{array}$ & $0.32^{*}$ & 0.17 * & $\begin{array}{l}0.11 \\
0.23\end{array}$ \\
\hline$\geq 40$ & $0.24^{*}$ & 0.14 * & $\begin{array}{l}0.11- \\
0.19\end{array}$ & $0.25^{\star}$ & $0.15^{\star}$ & $\begin{array}{l}0.11- \\
0.21\end{array}$ & 0.20 * & 0.10 * & $\begin{array}{l}0.07 \\
0.17\end{array}$ \\
\hline
\end{tabular}

\section{Religion}

\begin{tabular}{lcccccccccc} 
Christianity & 1.00 & 1.00 & \multicolumn{1}{c}{1.00} & \multicolumn{3}{c}{1.00} & 1.00 \\
Islam & $1.26^{*}$ & 1.06 & $\begin{array}{l}0.91- \\
1.18\end{array}$ & $1.35^{*}$ & 1.15 & $0.97-$ & $1.10^{*}$ & 0.91 & $\begin{array}{l}0.73- \\
1.12\end{array}$ \\
Others & & & & & 1.35 & & & \\
& 1.15 & 0.91 & $\begin{array}{l}0.52- \\
1.27\end{array}$ & $1.25^{*}$ & 1.04 & $0.64-$ & 0.95 & 0.67 & $0.29-$ \\
& & & & & 1.69 & & & 1.53
\end{tabular}

\section{Region}

\begin{tabular}{|c|c|c|c|c|c|c|c|c|c|}
\hline Northcentral & 1.00 & 1.00 & & 1.00 & 1.00 & & 1.00 & 1.00 & \\
\hline Northeast & $1.42^{\star}$ & $1.15^{\star}$ & $\begin{array}{l}1.02- \\
1.33\end{array}$ & $1.40 *$ & 1.09 & $\begin{array}{l}0.93- \\
1.29\end{array}$ & $1.49 *$ & $1.40 *$ & $\begin{array}{l}1.09- \\
1.78\end{array}$ \\
\hline Northwest & $1.52^{\star}$ & 1.08 & $\begin{array}{l}0.97- \\
1.26\end{array}$ & $1.53^{\star}$ & 1.09 & $\begin{array}{l}0.93- \\
1.28\end{array}$ & $1.49 *$ & 1.04 & $\begin{array}{l}0.83- \\
1.31\end{array}$ \\
\hline Southeast & $1.43^{\star}$ & $1.95^{\star}$ & $\begin{array}{l}1.59- \\
2.23\end{array}$ & $1.46^{*}$ & $2.09 *$ & $\begin{array}{l}1.66- \\
2.63\end{array}$ & $1.44^{*}$ & $1.75^{\star}$ & $\begin{array}{l}1.36- \\
2.26\end{array}$ \\
\hline Southsouth & $1.12^{\star}$ & $1.48^{*}$ & $\begin{array}{l}1.27- \\
1.79\end{array}$ & 1.07 & $1.42^{\star}$ & $\begin{array}{l}1.15- \\
1.76\end{array}$ & $1.26^{\star}$ & $1.56 *$ & $\begin{array}{l}1.16- \\
2.08\end{array}$ \\
\hline Southwest & $0.80 *$ & $0.82^{\star}$ & $\begin{array}{l}0.67- \\
0.95\end{array}$ & $0.82^{\star}$ & 0.90 & $\begin{array}{l}0.69- \\
1.17\end{array}$ & $0.80 *$ & $0.75^{\star}$ & $\begin{array}{l}0.58- \\
0.95\end{array}$ \\
\hline
\end{tabular}




\begin{tabular}{|c|c|c|c|c|c|c|c|c|c|}
\hline Higher & 1.00 & 1.00 & & & 1.00 & & 1.00 & 1.00 & \\
\hline Secondary & $0.83^{\star}$ & $0.88^{\star}$ & $\begin{array}{l}0.78- \\
0.99\end{array}$ & $0.77 *$ & 0.90 & $\begin{array}{l}0.77- \\
1.05\end{array}$ & 0.78 & 0.97 & $\begin{array}{l}0.76- \\
1.25\end{array}$ \\
\hline Primary & $0.97 \star$ & 1.06 & $\begin{array}{l}0.97- \\
1.29\end{array}$ & $0.83^{*}$ & 1.07 & $\begin{array}{l}0.92- \\
1.26\end{array}$ & $1.19 *$ & 1.24 & $\begin{array}{l}0.97- \\
1.57\end{array}$ \\
\hline No education & $1.63^{\star}$ & $1.45^{\star}$ & $\begin{array}{l}1.25- \\
1.89\end{array}$ & $1.64^{\star}$ & $1.58 *$ & $\begin{array}{l}1.17- \\
2.08\end{array}$ & $1.34^{\star}$ & $1.61^{\star}$ & $\begin{array}{l}1.19- \\
2.19\end{array}$ \\
\hline \multicolumn{10}{|l|}{ Marital status } \\
\hline Never married & 1.00 & & & & 1.00 & & 1.00 & 1.00 & \\
\hline Married & $1.16^{\star}$ & 1.11 & $\begin{array}{l}0.92- \\
1.34\end{array}$ & $1.23^{\star}$ & 0.99 & $\begin{array}{l}0.89- \\
1.10\end{array}$ & $1.21^{\star}$ & 1.26 & $\begin{array}{l}0.94- \\
1.69\end{array}$ \\
\hline \multicolumn{10}{|l|}{ Wealth index } \\
\hline Poor & 1.00 & 1.00 & & 1.00 & 1.00 & & 1.00 & 1.00 & \\
\hline Middle & $0.92 \star$ & $1.12^{\star}$ & $\begin{array}{l}1.01- \\
1.24\end{array}$ & $0.92^{\star}$ & $1.19 *$ & $\begin{array}{l}1.06- \\
1.35\end{array}$ & 0.95 & 0.94 & $\begin{array}{l}0.74- \\
1.18\end{array}$ \\
\hline Rich & $0.86^{*}$ & $1.13^{\star}$ & $\begin{array}{l}1.03- \\
1.33\end{array}$ & $0.86^{*}$ & 1.12 & $\begin{array}{l}0.95- \\
1.32\end{array}$ & $0.89 *$ & 1.08 & $\begin{array}{l}0.86- \\
1.35\end{array}$ \\
\hline \multicolumn{10}{|c|}{$\begin{array}{l}\text { Number of } \\
\text { children ever born }\end{array}$} \\
\hline $0-2$ & 1.00 & 1.00 & & 1.00 & 1.00 & & 1.00 & 1.00 & \\
\hline $3-4$ & $0.76 *$ & 0.69 & $\begin{array}{l}0.58- \\
1.05\end{array}$ & $0.45^{\star}$ & $0.21^{*}$ & $\begin{array}{l}0.03- \\
0.37\end{array}$ & $0.83^{*}$ & 0.96 & $\begin{array}{l}0.81- \\
1.13\end{array}$ \\
\hline$>4$ & $0.80 *$ & $0.82^{\star}$ & $\begin{array}{l}0.77- \\
0.96\end{array}$ & $0.73^{*}$ & $0.67 *$ & $\begin{array}{l}0.42- \\
0.96\end{array}$ & $0.65^{\star}$ & $0.24^{*}$ & $\begin{array}{l}0.22- \\
0.29\end{array}$ \\
\hline \multicolumn{10}{|l|}{$\begin{array}{l}\text { Antenatal care } \\
\text { visits }\end{array}$} \\
\hline None & 1.00 & 1.00 & & 1.00 & 1.00 & & 1.00 & 1.00 & \\
\hline $1-3$ & 1.07 & 1.03 & $\begin{array}{l}0.92- \\
1.15\end{array}$ & 1.03 & 1.02 & $\begin{array}{l}0.89- \\
1.16\end{array}$ & 1.15 & 1.06 & $\begin{array}{l}0.82- \\
1.36\end{array}$ \\
\hline $4-7$ & $0.91^{\star}$ & $0.87 \star$ & $\begin{array}{l}0.78- \\
0.96\end{array}$ & $0.89 *$ & $0.87 *$ & $\begin{array}{l}0.77- \\
0.98\end{array}$ & 0.95 & 0.87 & $\begin{array}{l}0.69- \\
1.08\end{array}$ \\
\hline$>7$ & $0.87 *$ & $0.86 *$ & $\begin{array}{l}0.75- \\
0.98\end{array}$ & 0.88 & $0.83^{*}$ & $\begin{array}{l}0.69- \\
0.99\end{array}$ & 0.86 & 0.87 & $\begin{array}{l}0.68- \\
1.11\end{array}$ \\
\hline
\end{tabular}

Table 2 shows the results of the analysis of association between birth interval and the women characteristics using logistic regression. The result indicates the impact of sociodemographic and health care related factors contributing to short birth interval in rural and urban Nigeria. The result indicated higher odds of short birth interval in rural areas ( $A O R=1.16,95 \% \mathrm{Cl}=0.96-1.16)$ compared to urban areas, 
though not statistically significant. Analysis showed a significant decrease in odds of short birth interval with increased maternal age in Nigeria (20-29 years: $A O R=0.40,95 \% \mathrm{Cl}=0.34-0.47 ; 30-39$ years: $A O R=0.22$, $95 \% \mathrm{Cl}=0.19-0.27 ; \geq 40$ years: $\mathrm{AOR}=0.15,95 \% \mathrm{Cl}=0.11-0.19)$; and Rural Nigeria (20-29 years: $\mathrm{AOR}=0.39$, $95 \% \mathrm{Cl}=0.33-0.47 ; 30-39$ years: $\mathrm{AOR}=0.24,95 \% \mathrm{Cl}=0.19-0.30 ; \geq 40$ years: $\mathrm{AOR}=0.15,95 \% \mathrm{Cl}=0.11-0.21$ ) and urban areas $((20-29$ years: $A O R=0.37,95 \% \mathrm{Cl}=0.27-0.51 ; 30-39$ years: $\mathrm{AOR}=0.17,95 \% \mathrm{Cl}=0.11-0.23$; $\geq 40$ years: $A O R=0.10,95 \% \mathrm{Cl}=0.07-0.17)$.

There was a significantly higher odds of having a short birth interval among rural women living in only the South-east (AOR=2.09, 95\% $\mathrm{Cl}=1.66-2.63$ ) and South-south ( $\mathrm{AOR}=1.42,95 \% \mathrm{Cl}=1.15-1.76)$. While among women residing in the urban areas, living in the North-east ( $A O R=1.41,95 \% \mathrm{Cl}=1.09-1.78$ ), Southeast $(A O R=1.75,95 \% \mathrm{Cl}=1.36-2.26)$ and South-south ( $A O R=1.56,95 \% \mathrm{Cl}=1.16-2.08)$ were significantly more likely to have short birth interval compared with those living in the North-central; whereas living in south-west urban Nigeria was significantly less likely to have short birth interval compared with those living in the North-central (AOR=0.75, 95\% $\mathrm{Cl}=0.58-0.95)$.

Whereas women who had no formal education were $61 \%$ and $58 \%$ significantly higher in odds of having short birth interval than women with higher education in urban Nigeria ( $A O R=1.61,95 \% \mathrm{Cl}=1.19-2.19)$ and rural Nigeria ( $A O R=1.58,95 \% \mathrm{Cl}=1.17-2.08)$ respectively. Regarding household wealth index, middle wealth index women living in the rural areas were 1.19 times more likely to have short birth intervals compared to poor women ( $A O R=1.19,95 \% \mathrm{Cl}=1.06-1.35)$. But in the urban areas, middle wealth index women had a lower odds of having short birth intervals than the poor women, though not statistically significant (AOR=0.94, 95\% $\mathrm{Cl}=0.74-1.18)$.

Women in rural Nigeria who have had three to four deliveries and above were less likely to have a short birth interval $(\mathrm{AOR}=0.21,95 \% \mathrm{Cl}=0.03-0.37)$ and $(\mathrm{AOR}=0.67,95 \% \mathrm{Cl}=0.42-0.96)$ respectively than those with two deliveries or less. In urban Nigerian only women who had more than 4 children were significantly more likely to have a short birth interval than women who had two children or less (AOR $=0.24,95 \%$ $\mathrm{Cl}=0.22-0.29$ ). But those who had 3-4 children had lower odds of having short birth intervals compared with women who had two children or less, though not statistically significant. Women who attended antenatal care at least four times during pregnancy had lower odds of having short birth intervals in only rural Nigeria than those who did not attend: Four to seven $A N C$ visits ( $A O R=0.87,95 \% \mathrm{Cl}=0.77-0.98)$ and more than seven ANC visits (AOR=0.83, 95\% $\mathrm{Cl}=0.69-0.99)$.

\subsection{Discussion}

This study was designed to assess short birth interval and its determinant with a focus on its rural-urban variation in Nigeria. We defined a short birth interval as having another birth before 24 months of having a preceding birth. The overall prevalence of short birth intervals in Nigeria was $20.6 \%$. While rural and urban areas of Nigeria were $20.7 \%$ and $20.3 \%$ respectively. This result is higher than the SBI reported in Rwanda, but lower compared to findings in some other African countries [5,11] as well as in Brazil [12]. The observed differences could be attributed to the prevalent socio-geographical and cultural differences 
in the studied areas. These results indeed call for urgent action considering the adverse consequences of short birth interval to mothers and child. Though all the variables were significantly associated with short birth intervals at the bivariate level, the multivariate analysis showed that maternal age at childbirth, geopolitical region, number of children ever born, and ANC visits were all statistically associated with short birth intervals. While the educational level was significant in urban areas, the household wealth index was significantly associated with short birth intervals in rural areas at a multivariate level. Though, both variables were significant in Nigeria.

This study showed that the odds of having a short birth interval decreases as the mother's age at birth of the child increases. In the other words, the odds of having the next child within 24 months is reduced as women get older, and this result agreed with previous studies [3,24]. Fecundity could be a possible explanation for this, as younger women are highly fecund than older women and the likelihood of younger women to use contraceptives is less compared to older women because they have a high desire to bear children [24]. More so, young women are likely to be poor and as such may not afford more birth spacing techniques compared to older women [25].

The study revealed that women residing in rural Nigeria were more likely to have short birth intervals compared with those residents in urban areas. This again substantiates the essence of this study, as it is believed that contributing factors to short birth interval is dependent on the place of residence, and as such could not be the same. This is consistent with reports of similar studies which indicate a relatively higher occurrence of short birth intervals in rural areas compared to urban areas [14, 26, 27]. This could be attributed to the relatively lower information on birth intervals and the nonavailability of modern contraceptives in rural areas compared to urban areas. Women who have information about short birth intervals through any media channel are expected to have a better understanding of the negative impact of short birth intervals on maternal and children's health. As a result, women who have no exposure to any media are more likely to experience short birth intervals than those who have media exposure [28, 29].

Whereas all the zones in the country except North-west were associated with high odds of having a short birth interval at the national level and rural areas, only south-east and south-south were significantly associated with high odds of having short birth interval among urban residence. This could be because of the under-utilization of contraceptives in all the regions in rural and urban Nigeria by both men and women [30].

The study also revealed that women that attended the WHO minimum four antenatal care visits were less likely to have a short birth interval than those that attended less than the minimum visits in rural Nigeria. This is because ANC attendees have access to health education that explains the consequences of short birth intervals and information and materials that will enable them to prolong pregnancy to their desired time. Having more than two children were less likely to have a short birth interval than having less for women residing in both rural and urban areas of Nigeria. This is true because these women that had 
more children may have achieved their desired family size and may feel less pressure or be in less of a hurry to get pregnant again [3].

This study has observed that Maternal education is protective of short birth intervals as an increase in educational attainment leads to a decrease in the likelihood of experiencing short birth intervals. This implies that educated women were more likely to have spaced births than non-educated women. This finding is consistent with other studies in Ethiopia and Pakistan [31-33]. The explanation might be attributed to the fact that better-educated women are more likely to use contraception to delay their interbirth intervals and may also be exposed to more health education. Furthermore, there is a likelihood that literate women may be engaged in careers that are not well-suited with childbearing [32, 34].

The household wealth index was also identified as significant determinant of short birth interval in rural Nigeria. This study revealed that odds of experiencing short birth intervals were less common in households in the rich and middle wealth index than in the poor wealth index. This is consistent with studies carried out in Ethiopia, Saudi Arabia [31,35]. The possible explanation for this could be that privileged women may have more access to health care education and information and could afford health care services that apply logically enhanced short interbirth interval [31]. Furthermore, married women have higher odds of experiencing short birth intervals than never-married women. The reason may be since married women are less likely to use contraceptives than the never-married women [36].

The major strength of this study was the fact that it utilized nationally representative data collected through standardized questionnaires and valid sampling procedures. While the limitation was on the ground that the design was cross-sectional which involves some missing information on reproductive indicators. Our findings should be interpreted with caution as we could not establish causation.

\subsection{Conclusion}

This study has demonstrated disparities of short birth interval in rural and urban Nigeria, by estimating prevalence and identifying factors influencing short birth intervals in these areas. There were slight disparities in the prevalence of short birth intervals in rural and urban areas. This is evident in the contributing factors as almost all the same factors such as maternal age at childbirth, geopolitical regions, educational attainment, and the number of children ever born was significantly associated with short birth intervals in both areas. It only differed in wealth index and the ANC visits for rural areas. Thus, policymakers and the relevant stakeholders should intensify existing strategies geared towards maintaining optimal birth spacing to ensure the wellbeing of mothers and children in rural and urban areas of Nigeria. Public health awareness campaigns should be strengthened to drive the importance of birth spacing techniques such as the utilization of modern contraceptives and breastfeeding in all the geo-political regions and across age strata. Finally, women, particularly in the rural areas should be encouraged to advance their education to at least secondary level and enlightened on the importance of ANC. 


\section{Declarations}

\section{Ethics statement}

The studies involving human participants were reviewed and approved by The Rivers State Health Research Ethics Committee approved the study (Number: RSHMB/RSHREC/ 11.21/VOL.9/042). Written informed consent to participate in this study was provided by the participants' legal guardian/next of kin. All methods were performed in accordance with the relevant guidelines and regulations from ICF Macro USA.

\section{Conflict of interest}

The authors declared no conflict of interest

\section{Author contributions}

AW and CE contributed to conception and study design. AW, AB, CKE, GK, LS and AFF authors performed the statistical analysis and interpretation of results and the drafting of the manuscripts. All authors reviewed the statistical analysis and revised the manuscript draft. All authors read and approved the final manuscript.

\section{Acknowledgments}

We thank ICF Macro for granting access to the data.

\section{Availability of data and materials}

The data that support the findings of the current study are available in the DHS repository at www.dhsprogram.com

\section{References}

1. Agida TE, Akaba GO, Ekele BA, Isah D. Practice of healthy timing and spacing of pregnancy (HSTP), experience from a low resource setting. Trop J Obstet Gynaecol. 2016;33:57-63.

2. Dim CC, Ugwu EO, Iloghalu El. Duration and determinants of inter-birth interval among women in Enugu, south-eastern Nigeria. J Obstet Gynaecol (Lahore). 2013;33:175-9.

3. de Jonge HCC, Azad K, Seward N, Kuddus A, Shaha S, Beard J, et al. Determinants and consequences of short birth interval in rural Bangladesh: A cross-sectional study. BMC Pregnancy Childbirth. 2014;14:17.

4. World Health Organisation. Report of a WHO technical consultation on birth spacing. Rep a WHO Tech Consult Birth Spacing. 2005;13:1-44. 
5. Ajayi Al, Somefun OD. Patterns and determinants of short and long birth intervals among women in selected sub-Saharan African countries. Medicine (Baltimore). 2020;99:e20118.

6. Pimentel J, Ansari U, Omer K, Gidado Y, Baba MC, Andersson N, et al. Factors associated with short birth interval in low- And middle-income countries: A systematic review. BMC Pregnancy Childbirth. 2020;20:156.

7. Wegbom Al, Essi ID, Kiri VA. Survival Analysis of Under-five Mortality and Its Associated Determinants in Nigeria: Evidence from a Survey Data. Int J Stat Appl. 2019;2019:59-66.

8. Wegbom Al, Edet CK, Kir VA. Prevalence, Trends and Predictors of Small Size Babies in Nigeria: Analysis of Data from Two Recent Nigeria Demographic and Health Surveys. Int J Child Heal Nutr. 2020;9:115-24.

9. Perin J, Walker N. Potential confounding in the association between short birth intervals and increased neonatal, infant, and child mortality. Glob Health Action. 2015;8:1-9.

10. National Population Commission(NPC)[Nigeria] and ICF. 2019. Nigeria Demographic and Health Survey 2018. Abuja, Nigeria, And Rockville, Maryland, USA: NPC and ICF; 2019.

11. Gebrehiwot SW, Abera G, Tesfay K, Tilahun W. Short birth interval and associated factors among women of child bearing age in northern Ethiopia, 2016. BMC Womens Health. 2019;19:85.

12. Barbosa R, Alves MTSSB, Nathasje I, Chagas D, Simões VF, Silva L. Factors Associated with Inadequate Birth Intervals in the BRISA Birth Cohort, Brazil. Rev Bras Ginecol e Obstet. 2020;42:67-73.

13. Akinyemi JO, Odimegwu CO, Banjo OO, Gbadebo BM. Clustering of infant deaths among Nigerian women: investigation of temporal patterns using dynamic random effects model. Genus. 2019;75.

14. Fayehun O, Omololu F, Isiugo-Abanihe U. Sex of preceding child and birth spacing among Nigerian ethnic groups. Afr J Reprod Health. 2011;15:79-89.

15. Schwandt HM, Skinner J, Hebert LE, Cobb L, Saad A, Odeku M. Inadequate birth spacing is perceived as riskier than all family planning methods, except sterilization and abortion, in a qualitative study among urban Nigerians. BMC Womens Health. 2017;17:1-9.

16. Akinyemi JO, Afolabi Bamgboye E, Ayeni O. New trends in under-five mortality determinants and their effects on child survival in Nigeria: A review of childhood mortality data from 1990-2008. Etude la Popul Africaine. 2012;27:25-42.

17. Wegbom Al, Wokoma DSA, Nnoka LC, Onyesom C. What Explains The High Rate of Infant Mortality in Rural Nigeria: Biodemographic or Socioeconomic Factors? Int J Heal Sci Res. 2016;6:317. 
18. Getachew Y, Bekele S. Survival Analysis of Under-Five Mortality of Children and its Associated Risk Factors in Ethiopia. J Biosens Bioelectron. 2016;7.

19. Woldeamanuel BT. Socioeconomic, Demographic, and Environmental Determinants of Under-5 Mortality in Ethiopia: Evidence from Ethiopian Demographic and Health Survey, 2016. Child Dev Res. 2019;2019.

20. Adebowale SA, Morakinyo OM, Ana GR. Housing materials as predictors of under-five mortality in Nigeria: Evidence from 2013 demographic and health survey. BMC Pediatr. 2017;17.

21. Bassey G, Nyengidiki T, Dambo N. Determinants of interpregnancy interval among parturient in Port Harcourt, Nigeria. Sahel Med J. 2016;19:180.

22. Owonikoko K, Adeniji O, Oke O, Fawole A, Adeniji A. Determinants of inter-pregnancy interval in Ogbomoso: an unmet need for contraceptive usage. Int J Reprod Contraception, Obstet Gynecol. 2015;4:316.

23. Onubogu CU, Ugochukwu EF. Inter-pregnancy interval and pregnancy outcomes among HIV positive mothers in Nnamdi Azikiwe University Teaching Hospital, Nnewi, South-East Nigeria. Niger J Paediatr. 2013;40:264-269-269.

24. Shallo SA, Gobena T. Duration of Birth Interval and Associated Factors among Married Women Journal of Health Education Research. J Heal Educ Res Dev. 2019;7:1-9.

25. Berg V, Miettinen A, Jokela M, Rotkirch A. Shorter birth intervals between siblings are associated with increased risk of parental divorce. PLoS One. 2020;15:1-17.

26. Molitoris J, Barclay K, Kolk M. When and Where Birth Spacing Matters for Child Survival: An International Comparison Using the DHS. Demography. 2019;56:1349-70.

27. Nisha MK, Alam A, Islam MT, Huda T, Raynes-Greenow C. Risk of adverse pregnancy outcomes associated with short and long birth intervals in Bangladesh: Evidence from six Bangladesh Demographic and Health Surveys, 1996-2014. BMJ Open. 2019;9.

28. Islam MZ, Review S, Quarter F. Mohammad Zahidul Islam Khan *. 2016;7:26-49.

29. Damtie Y, Kefale B, Yalew M, Arefaynie M, Adane B. Short birth spacing and its association with maternal educational status, contraceptive use, and duration of breastfeeding in Ethiopia. A systematic review and metaanalysis. PLoS One. 2021;16 2 February:1-15.

30. Fayehun F. Contraceptive Use in Nigeria is incredibly low. A lack of knowledge may be why. 2017.

31. Hailu D, Gulte T. Determinants of Short Interbirth Interval among Reproductive Age Mothers in Arba Minch District, Ethiopia. Int J Reprod Med. 2016;2016:1-17. 
32. Begna Z, Assegid S, Kassahun W, Gerbaba M. Determinants of inter birth interval among married women living in rural pastoral communities of southern Ethiopia: A case control study. BMC Pregnancy Childbirth. 2013;13.

33. Asifa K, Muhammad KP. Determinants of Higher Order Birth Intervals in Pakistan. J Stat. 2012;19:5482.

34. ICPD \& MDGs. ICPD and the MDGs: Working as One. 2009;15:1-194.

35. Abdel-Fattah M, Hifnawy T, El Said TI, Moharam MM, Mahmoud MA. Determinants of birth spacing among saudi women. J Family Community Med. 2007;14:103-11.

36. Wang W, Staveteig S, Winter R, Allen C. Women's marital status, contraceptive use, and unmet need in Sub-Saharan Africa, Latin America, and the Caribbean. DHS Comp Rep No 44. 2017; July.

\section{Figures}

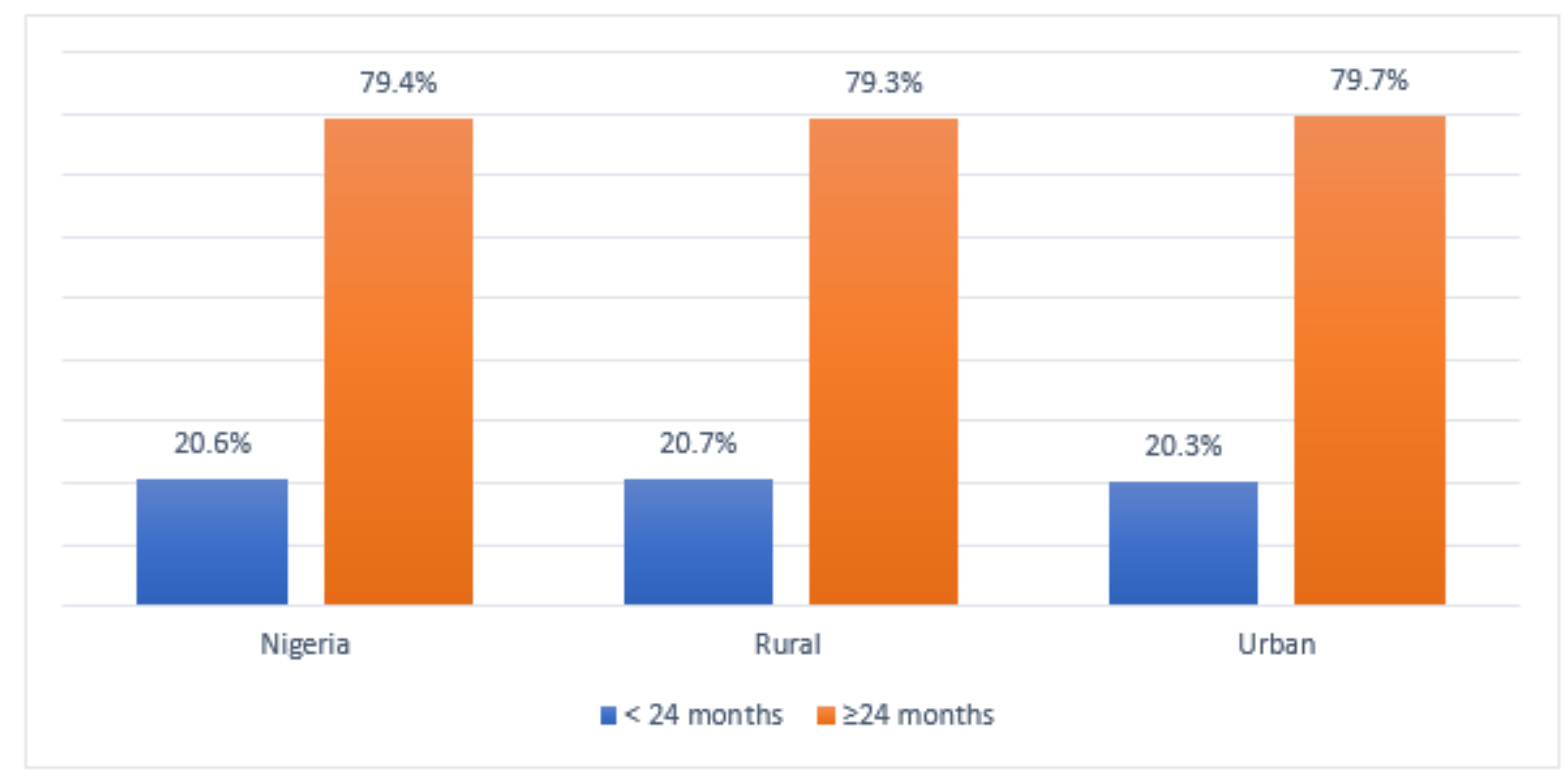

\section{Figure 1}

Disparities in proportion of birth interval in Nigeria 